\title{
Blood advanced glycation end products and biomarkers of inflammation in class III obese Brazilian subjects
}

\author{
Thiago Lenoir da Silva ${ }^{1}$, Rose Marie Muller Linhares ${ }^{2,3}$, Aline Pertile Remor ${ }^{1}$, Karina Ghisoni ${ }^{1}$, Roberta de Paula Martins ${ }^{1}$, Anicleto Poli ${ }^{4}$ \\ Aderbal Aguiar Jr ${ }^{1}$, Marcelo Fernando Ronsoni ${ }^{3}$, Alexandre Hohl ${ }^{3}$, Roger Walz ${ }^{3,5,6}$ and Alexandra Latini ${ }^{1 *}$ \\ ${ }^{1}$ Laboratório de Bioenergética e Estresse Oxidativo (LABOX), Departamento de Bioquímica, Centro de Ciências Biológicas, Universidade Federal de Santa \\ Catarina, UFSC, Florianópolis/SC, Brazil \\ ${ }^{2}$ Departamento de Pediatria, Hospital Universitário, Universidade Federal de Santa Catarina, UFSC, Florianópolis/SC, Brazil \\ ${ }^{3}$ Departamento de Clínica Médica, Hospital Universitário, Universidade Federal de Santa Catarina, UFSC, Florianópolis/SC, Brazil \\ ${ }^{4}$ Departamento de Farmacologia, Centro de Ciências Biológicas, Universidade Federal de Santa Catarina, UFSC, Florianópolis/SC, Brazil \\ ${ }^{5}$ Centro de Neurociências Aplicadas, Hospital Universitário, Universidade Federal de Santa Catarina, UFSC, Florianópolis/SC, Brazil \\ ${ }^{6}$ Centro de Epilepsia do Estado de Santa Catarina, CEPESC, Hospital Universitário, Universidade Federal de Santa Catarina, UFSC, Florianópolis/SC, Brazil
}

Metabolic syndrome is a constellation of disorders, including hypertension, dyslipidemia, hyperglycemia, and obesity, that predisposes to the development of type 2 diabetes and ultimately to an increased risk of cardiovascular death [1]. A key component, obesity is one of the main contributors to the worldwide problem of chronic diseases and disability. Obesity has reached epidemic proportions globally; in 2014 almost two billion adults were overweight, with more than 600 millions of them clinically classified as obese individuals [2]. Body mass index (BMI) - the weight in kilograms divided by the square of the height in meters $\left(\mathrm{kg} / \mathrm{m}^{2}\right)$ - is a commonly used index to classify obesity in adults. As WHO defines the terms, "overweight" is a BMI equal to or more than 25 , "obesity" is a BMI equal to or more than 30 , and obesity class III is when BMI is equal to or more than 40 [2].

In order to prevent or delay the onset of obesity and/or its linked complications with a successful therapeutic intervention, much effort is being invested in establishing new blood biomarkers. For example, the risk for obese individuals to develop type 2 diabetes or a heart attack has already been linked to blood markers of inflammation [3] and of glycotoxicity [4]. Here, we investigated whether markers of inflammation, including high-sensitive $\mathrm{c}$ reactive protein and neopterin levels, and markers of sustained hyperglycemia, such as, glycated hemoglobin and advanced glycation end products (AGEs), correlated with HOMA-IR (homeostasis model assessment-insulin resistance), LAP (lipid accumulation product, which predicts the incidence of cardiovascular diseases; blood and the anthropometric marker) and the Framingham score (estimates risk of heart attack in ten years) in class III obese Brazilian individuals.

\section{Subjects and methods}

This is an observational and transversal study in which 30 class III obese patients from Florianopolis, Santa Catarina, Brazil agreed to participate. The control group was composed of ten overweight volunteers. The local Research Ethics Committee approved the study and informed consent was collected from the participants (Protocol \# 2150/2011). Tables 1 and 2 show the clinical characteristics and biochemical data collected at the Endocrinology and Metabiology Clinic at Hospital Universitario, Universidade Federal de Santa Catarina, Florianópolis/SC, Brazil, between June, 2012 and March of 2013.
HOMA-IR, LAP and the Framingham score were calculated as previously described [5-7]. The clinical biochemical data were determined in a biochemical autoanalyser Dimension RxL (Siemens Healthcare Diagnostics Inc., EUA). Neopterin concentrations were determined by high-performance liquid chromatography coupled with fluorescence detection as previously reported by our group [8,9], and values were expressed as $\mu \mathrm{mol} / \mathrm{L}$. AGEs were measured by fluorimetry (Tecan, Grödig/ Salzburg, Austria), as previously reported [10].

\section{Findings/Discussion}

As depicted in Tables 1 and 2, the class III obese subjects presented insulin resistance, high probability of developing cardiovascular diseases, and also a high risk of heart attack in ten years, and almost half of this group was under pharmacological treatment with losartan (angiotensin II receptor antagonist for the treatment of hypertension) or losartan plus metformin (oral antidiabetic agent). Class III obese patients presented increased levels of high-sensitivity c-reactive protein (hsCRP) and neopterin (Table 2 and Figure 1A), pointing to an active inflammatory status.

Chronic inflammation has been linked to beta-cell dysfunction and insulin resistance, and the increased blood levels of these biomarkers may predict the development of type 2 diabetes and cardiovascular diseases $[7,11,12]$. Moreover, diabetes is an independent risk factor for cardiovascular disease, conferring an increased risk of morbidity and mortality from coronary artery disease, heart failure, and stroke [13]. In this context, hypertension accounts for more than $80 \%$ of diabetesrelated deaths [14]. The renin-angiotensin-aldosterone system (RAAS) is one of the most important hormonal mechanisms pharmacologically targeted to regulate blood pressure. Blocking this system produced

Correspondence to: Alexandra Latini, Laboratório de Bioenergética e Estresse Oxidativo (LABOX), Departamento de Bioquímica, Centro de Ciências Biológicas, Universidade Federal de Santa Catarina - UFSC, Campus Universitário - Córrego Grande, Bloco C-201/214, Florianópolis - SC, 88040900, Brazil, Tel: +55 483721 4743; Fax: +55 483721 9672; E-mail: a.latini@ufsc.br

Received: March 02, 2017; Accepted: March 23, 2017; Published: March 27,2017 

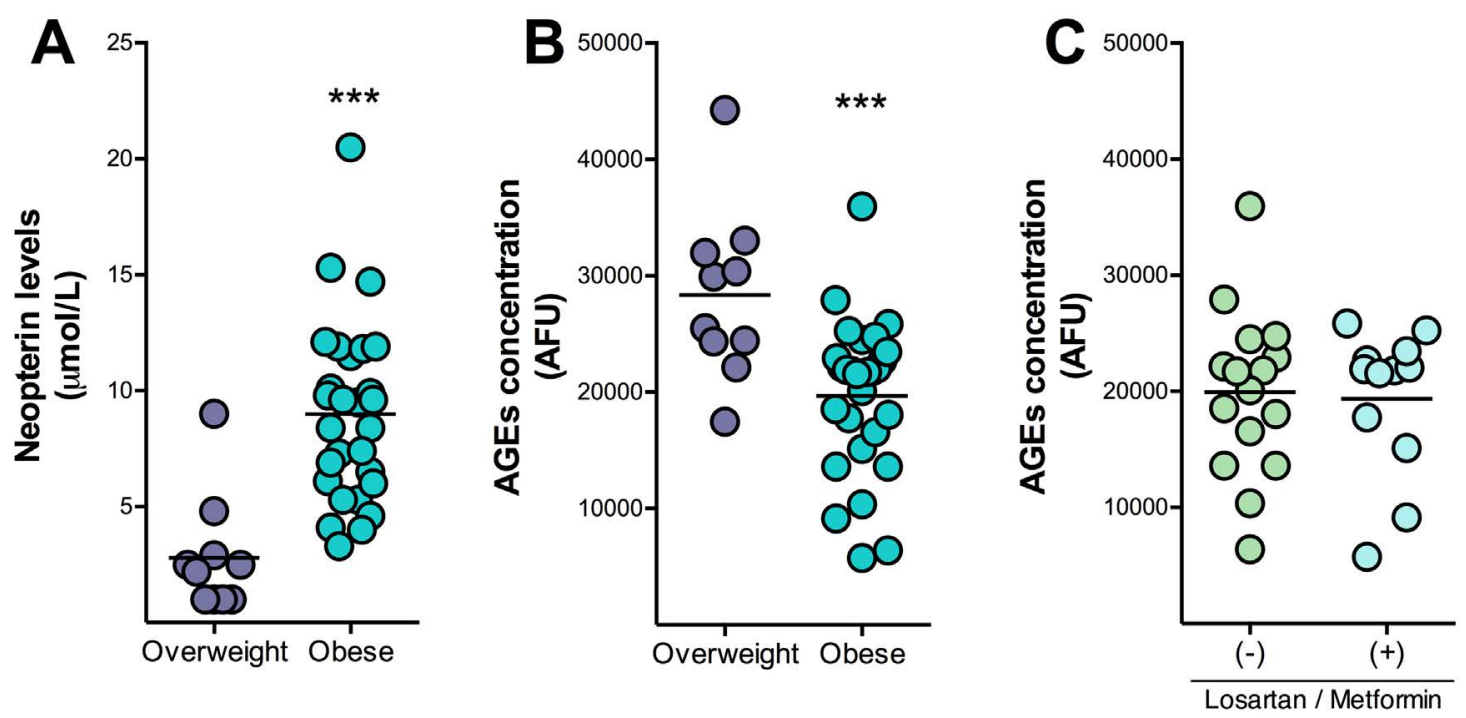

Figure 1. Blood levels of neopterin (A) and advanced glycated end products (B; AGEs) in class III obese individuals $(n=30)$ and overweight subjects $(n=10)$. AGEs were also measured under treatment with losartan ( $10 \mathrm{mg}$ /day) and or plus metformine (500 mg orally twice a day) (C). Values represent the mean \pm SD. ${ }^{*} P<0.05$; ${ }^{* * * *} P<0.001$, compared to the overweight group (Student $t$ Test).

Table 1. Clinical characteristics of the Brazilian obese patients.

\begin{tabular}{|c|c|c|c|c|}
\hline \multicolumn{3}{|c|}{ Clinical characteristics } & $\begin{array}{l}\text { Class III Obese } \\
\text { subjects } \\
(n=30)\end{array}$ & $\begin{array}{l}\text { Overweight subjects } \\
\qquad(n=10)\end{array}$ \\
\hline \multicolumn{3}{|c|}{ Age (years) } & $40.6 \pm 10.9$ & $48 \pm 13.0$ \\
\hline \multicolumn{3}{|c|}{ Female $(n ; \%)$} & $23 ; 76.7$ & $7 ; 70.0$ \\
\hline \multicolumn{3}{|c|}{$\begin{array}{c}\mathrm{BMI}\left(\mathrm{kg} / \mathrm{m}^{2}\right) \\
\text { Normal range - WHO criteria: } 18.5- \\
24.9[2]\end{array}$} & $49.5 \pm 8.2$ & 27.81 .4 \\
\hline \multicolumn{3}{|c|}{ Weight $(\mathrm{kg})$} & $131.6 \pm 31.1$ & $67.8 \pm 7.0$ \\
\hline \multicolumn{3}{|c|}{ Abdominal circumference $(\mathrm{cm})$} & $135.3 \pm 16.6$ & $89.6 \pm 8.3$ \\
\hline \multicolumn{3}{|c|}{ Waist circumference $(\mathrm{cm})$} & $139.0 \pm 15.9$ & $94.8 \pm 9.8$ \\
\hline \multicolumn{3}{|c|}{ Familiar history of obesity $(n ; \%)$} & $26 ; 86.7$ & $1 ; 10.0$ \\
\hline \multicolumn{3}{|c|}{ Type 2 diabetes $(n ; \%)$} & $11 ; 36.7$ & $1 ; 10.0$ \\
\hline \multicolumn{3}{|c|}{ Under physical activity $(n ; \%)$} & $7 ; 23.3$ & $5 ; 50$ \\
\hline \multicolumn{3}{|c|}{ Specific diets $(n ; \%)$} & $28 ; 93.3$ & $6 ; 60$ \\
\hline \multicolumn{3}{|c|}{ Smokers $(n ; \%)$} & $5 ; 16.7$ & $0 ; 0.0$ \\
\hline \multicolumn{3}{|c|}{$\begin{array}{c}\text { HOMA-IR } \\
\text { Homeostasis model assessment-insulin } \\
\text { resistance: cutoff determined for the } \\
\text { Brazilian population }=2.71[5]\end{array}$} & $6.35 \pm 0.7$ & ND \\
\hline \multicolumn{3}{|c|}{$\begin{array}{c}\text { LAP }(\mathrm{cm} . \mathrm{mmol} / \mathrm{L}) \\
\text { Lipid accumulation product: predicts } \\
\text { the incidence of cardiovascular } \\
\text { diseases: }[6] \\
25-49 \text { years; } 25-75^{\text {th }} \text { percentile: } 16.4-57.3 \\
>50 \text { years; } 25-75^{\text {th }} \text { percentile: } 31.1-85.3\end{array}$} & $131.1 \pm 94.4$ & ND \\
\hline \multicolumn{3}{|c|}{ Framingham score $(\%)[7]$} & & \multirow[b]{2}{*}{ ND } \\
\hline \begin{tabular}{|c} 
Points \\
6 \\
12 \\
$18+$
\end{tabular} & $\begin{array}{c}\text { Female } \\
3.3 \\
8.6 \\
21.6\end{array}$ & $\begin{array}{c}\text { Male } \\
4.7 \\
13.2 \\
>30\end{array}$ & $\begin{array}{c}\text { Female: } 7.3 \pm 9.4 \\
\text { Male: } 10.515 .1\end{array}$ & \\
\hline \multicolumn{3}{|c|}{ Systolic blood pressure (mmHg) } & $132.5 \pm 13.7$ & ND \\
\hline \multicolumn{3}{|c|}{ Diastolic blood pressure (mmHg) } & $86.7 \pm 11.5$ & ND \\
\hline \multicolumn{3}{|c|}{ Losartan or Losartan plus Metformin $(n ; \%)$} & $14 ; 46.7$ & $1 ; 10.0$ \\
\hline
\end{tabular}

protective effects in the kidney and heart in type 1 and 2 diabetic patients and it also stabilized blood pressure [15]. The molecular mechanisms are still not completely defined; however, it was demonstrated that angiotensin II (Ang II) is not only generated in the circulation by renin and the angiotensin converting enzymes, but it is also locally produced in diverse organs, including the kidneys, blood vessels, heart, adrenals, brain and also macrophages [16]. Most of this Ang II is not regulated by systemic hemodynamic changes, and via paracrine and autocrine signaling it mediates oxidative stress, inflammation, and fibrosis [17-19]. In this scenario, it could be suggested that hsCRP levels did not correlate with the clinical indexes - HOMA-IR, LAP or the Framingham score - of the class III obese patients (Table 2), due to the lack of anti-inflammatory effect of losartan (inhibitor of the RAAS; Ang II receptor blocker).

Neopterin, a pteridine mainly synthesized by activated macrophages in the periphery, is a sensitive marker of inflammation, immune system activation and an active participant in cardiovascular diseases [20]. Increased levels of neopterin are elevated in patients with coronary and peripheral artery disease and seem to be a prognostic marker for major adverse cardiovascular events. In particular, neopterin levels predict future major cardiac and vascular adverse events in patients presenting chronic coronary artery disease, and acute coronary syndromes [2123]. However, this biomarker did not correlate with the clinical scores, even when the class III obese patients displayed peripheral inflammation and high risk for developing type 2 diabetes and heart diseases (Table 1). However, it is known that high levels of hsCRP and neopterin are associated with high risk for cardiovascular diseases. Here, the biochemical data did not correlate with the clinical scores, suggesting that there could exist a clinical threshold from which these biomarkers may predict the development of the disease. Accordingly, Uribarri et al. [4] suggested that more specific and sensitive biomarkers are needed to identify healthy from unhealthy obese subjects.

Figure $1 \mathrm{~B}$ and $\mathrm{C}$ show that AGEs levels were unexpectedly reduced in the blood from class III obese subjects, and the losartan/metformin therapy did not induce any alterations. AGEs are a group of prooxidant, cytotoxic compounds that contribute to chronic inflammation and diabetic complications [24-26]. AGEs are mainly formed because of the accumulation of the highly reactive methylglyoxal during hyperglycemic conditions [27]. Increased AGEs levels promote inflammation and oxidative stress through the activation of the cell surface receptors of AGE (RAGE), as well as directly modify the 
Table 2. Altered blood biomarkers in type III obese Brazilian individuals.

\begin{tabular}{|c|c|}
\hline Biomarker concentration & $\begin{array}{c}\text { Class III Obese subjects } \\
\text { (Range reference values is given in } \\
\text { parenthesis) }[7] \\
\text { Values are } \mathrm{X} \pm \mathrm{SD}\end{array}$ \\
\hline Glucose (mg/dL) & $\begin{array}{c}117.7 \pm 40.3 \\
(70-99)\end{array}$ \\
\hline Insulin $(\mu \mathrm{IU} / \mathrm{mL})$ & $\begin{array}{l}19.9 \pm 13.8 \\
(5-20)\end{array}$ \\
\hline $\mathrm{HbA1C}(\%)$ & $\begin{array}{l}6.82 \pm 1.4 \\
(4-6)\end{array}$ \\
\hline Triglycerides (mg/dL) & $\begin{array}{l}157.4 \pm 115.4 \\
\quad(<100)\end{array}$ \\
\hline Total cholesterol (mg/dL) & $\begin{array}{l}175.7 \pm 41.0 \\
(<200)\end{array}$ \\
\hline High-density lipoprotein-cholesterol (mg/dL) & $\begin{array}{l}41.5 \pm 16.7 \\
\quad(>40)\end{array}$ \\
\hline Low-density lipoprotein-cholesterol (mg/dL) & $\begin{array}{l}109.0 \pm 32.0 \\
(<130)\end{array}$ \\
\hline Aspartate aminotransferase (U/L) & $\begin{array}{l}46.1 \pm 17.5 \\
(20-48)\end{array}$ \\
\hline Alanine transaminase $(\mathrm{U} / \mathrm{L})$ & $\begin{array}{l}27.4 \pm 17.3 \\
(10-40)\end{array}$ \\
\hline Gamma-glutamyl transferase (U/L) & $\begin{array}{c}48.1 \pm 26.2 \\
(30-50)\end{array}$ \\
\hline High-sensitivity c-reactive protein (mg/L) & $\begin{array}{c}7.5 \pm 3.4 \\
(<3.0) \\
(\text { overweight subjects: } 1.6 \pm 0.8) \\
(P<0.001 ; \text { effect size: } 4.11) \\
\text { Losartan/metformin }(\mathrm{n}=14): \\
7.3 \pm 3.3 \\
\text { No losartan/metformin }(\mathrm{n}=16): \\
7.3 \pm 3.7 \\
\text { (Losartan/metformin vs. no drugs; } P<0.05)\end{array}$ \\
\hline
\end{tabular}

extracellular matrix and action of hormones [28]. Here, we found reduced AGES levels in class III obese subjects, when comparing with the control group composed by overweight individuals. As glycated hemoglobin $(\mathrm{HbAlC})$ levels positively and significantly correlated with blood AGEs in class III obese subjects $(P<0.05)$, it could be suggested AGEs in obese individuals are originated from the glucose metabolism. Unfortunately, $\mathrm{HbA1C}$ in overweight individuals was not measured; therefore, it cannot be suggested that the higher levels of AGEs in this group was linked mainly to dietary factors, as consistently pointed out by many researchers [26,28-30]. Nonetheless, AGEs levels in obese subjects did not correlate with higher risk of cardiovascular diseases.

\section{Conclusions}

hsCRP, neopterin, glycated hemoglobin and AGEs levels did not correlate with the clinical scores, HOMA-IR, LAP and the Framingham score. Considering the vast literature demonstrating the intricate relationship between the biomarkers and the prediction of heart diseases development, we suggest that in these class III obese patients there is an unknown modifiable factor which is mascaraing the clinical / biochemical associations, or as suggested it is needed more specific and sensitive biomarkers to identify healthy from unhealthy obese subjects, who are at risk for cardiovascular disorders.

\section{Acknowledgements}

The authors are grateful to Ted Griswold for language editing. This work was supported by grants from $\mathrm{CNPq}$ (Conselho Nacional de Desenvolvimento Científico e Tecnológico), NENASC/Programa de Apoio aos Núcleos de Excelência (PRONEX), and CAPES (Coordenação de Aperfeiçoamento de Pessoal de Nível Superior). RW and $\mathrm{AL}$ are $\mathrm{CNPq}$ fellows.

\section{References}

1. Alberti K, Eckel RH, Grundy SM, Zimmet PZ, Cleeman J, et al. (2009) Harmonizing the metabolic syndrome: a joint interim statement of the International Diabetes Federation Task Force on Epidemiology and Prevention; National Heart, Lung, and Blood Institute; American Heart Association; World Heart Federation; International Atherosclerosis Society; and International Association for the Study of Obesity. Circulation 120: 1640-1645.

2. WHO (2016) Obesity and overweight. In World Health Organization.

3. Koh KK, Han SH, Quon MJ (2005) Inflammatory markers and the metabolic syndrome: insights from therapeutic interventions. J Am Coll Cardiol 46: 1978-1985. [Crossref]

4. Uribarri J, Cai W, Woodward M, Tripp E, Goldberg L, et al. (2015) Elevated serum advanced glycation endproducts in obese indicate risk for the metabolic syndrome: a link between healthy and unhealthy obesity? J Clin Endocrinol Metab 100: 1957-1966.

5. Geloneze B, Repetto EM, Geloneze SR, Tambascia MA, Ermetice MN (2006) The threshold value for insulin resistance (HOMA-IR) in an admixtured population IR in the Brazilian Metabolic Syndrome Study. Diabetes Res Clin Pract 72: 219-220.

6. Kahn HS (2005) The "lipid accumulation product" performs better than the body mass index for recognizing cardiovascular risk: a population-based comparison. BMC Cardiovasc Disord 5: 26

7. Xavier H, Izar MC, Faria Neto JR, Assad MH, Rocha VZ, et al. (2013) V Diretriz Brasileira de Cardiologia. (Sociedade Brasileira de Cardiologia).

8. de Lucas RD, Caputo F, Mendes de Souza K, Sigwalt AR, Ghisoni K, et al. (2014) Increased platelet oxidative metabolism, blood oxidative stress and neopterin levels after ultra-endurance exercise. J Sports Sci 32: 22-30.

9. Ghisoni K, Martins Rde P, Barbeito L, Latini A (2015) Neopterin as a potential cytoprotective brain molecule. J Psychiatr Res 71: 134-139. [Crossref]

10. Remor AP, de Matos FJ, Ghisoni K, da Silva TL, Eidt G, et al. (2011) Differential effects of insulin on peripheral diabetes-related changes in mitochondrial bioenergetics: involvement of advanced glycosylated end products. Biochim Biophys Acta 1812: 1460-1471.

11. Ridker PM, Cushman M, Stampfer MJ, Tracy RP, Hennekens CH (1997) Inflammation, aspirin, and the risk of cardiovascular disease in apparently healthy men. $N$ Engl J Med 336: 973-979.

12. Ridker PM, Hennekens CH, Buring JE, Rifai N (2000) C-reactive protein and other markers of inflammation in the prediction of cardiovascular disease in women. $\mathrm{NEngl}$ $J$ Med 342: 836-843. [Crossref]

13. Cowie CC, Rust KF, Ford ES, Eberhardt MS, Byrd-Holt DD, et al. (2009) Full accounting of diabetes and pre-diabetes in the U.S. population in 1988-1994 and 20052006. Diabetes Care 32: 287-294. [Crossref]

14. [No authors listed] (1993) Hypertension in Diabetes Study (HDS): II. Increased risk of cardiovascular complications in hypertensive type 2 diabetic patients. J Hypertens 11: 319-325. [Crossref]

15. Ruggenenti P, Cravedi P, Remuzzi G (2010) The RAAS in the pathogenesis and treatment of diabetic nephropathy. Nat Rev Nephrol 6: 319-330. [Crossref]

16. Bader M, Ganten D (2008) Update on tissue renin-angiotensin systems. J Mol Med (Berl) 86: 615-621.

17. Griendling KK, Ushio-Fukai M (2000) Reactive oxygen species as mediators of angiotensin II signaling. Regul Pept 91: 21-27. [Crossref]

18. Li C, Sun BK, Lim SW, Song JC, Kang SW, et al. (2005) Combined effects of losartan and pravastatin on interstitial inflammation and fibrosis in chronic cyclosporineinduced nephropathy. Transplantation 79: 1522-1529.

19. Ruiz-Ortega M, Esteban V, Ruperez M, Sanchez-Lopez E, Rodriguez-Vita J, et al (2006) Renal and vascular hypertension-induced inflammation: role of angiotensin II. Curr Opin Nephrol Hypertens 15: 159-166.

20. De Rosa S, Cirillo P, Pacileo M, Petrillo G, D’Ascoli GL, et al. (2011) Neopterin: from forgotten biomarker to leading actor in cardiovascular pathophysiology. Curr Vasc Pharmacol 9: 188-199.

21. Avanzas P, Arroyo-Espliguero R, Quiles J, Roy D, Kaski JC (2005) Elevated serum neopterin predicts future adverse cardiac events in patients with chronic stable angina pectoris. Eur Heart $J$ 26: 457-463.

22. Garcia-Moll X, Cole D, Zouridakis E, Kaski JC (2000) Increased serum neopterin: a marker of coronary artery disease activity in women. Heart 83: 346-350. [Crossref] 
23. Sugioka K, Naruko T, Matsumura Y, Shirai N, Hozumi T, et al. (2010) Neopterin and atherosclerotic plaque instability in coronary and carotid arteries. J Atheroscler Thromb 17: 1115-1121. [Crossref]

24. Kilhovd BK, Juutilainen A, Lehto S, Ronnemaa T, Torjesen PA, et al. (2007) Increased serum levels of advanced glycation endproducts predict total, cardiovascular and coronary mortality in women with type 2 diabetes: a population-based 18 year followup study. Diabetologia 50: 1409-1417.

25. Tan KC, Chow WS, Ai VH, Metz C, Bucala R, et al. (2002) Advanced glycation end products and endothelial dysfunction in type 2 diabetes. Diabetes Care 25: 1055-1059. [Crossref]

26. Vlassara H, Striker GE (2011) AGE restriction in diabetes mellitus: a paradigm shift. Nat Rev Endocrinol 7: 526-539. [Crossref]
27. Brownlee M (2005) The pathobiology of diabetic complications: a unifying mechanism. Diabetes 54: 1615-1625. [Crossref]

28. Ajith TA, Vinodkumar P (2016) Advanced Glycation End Products: Association with the Pathogenesis of Diseases and the Current Therapeutic Advances. Curr Clin Pharmacol 11: 118-127. [Crossref]

29. Birlouez-Aragon I, Saavedra G, Tessier FJ, Galinier A, Ait-Ameur L, et al. (2010) A diet based on high-heat-treated foods promotes risk factors for diabetes mellitus and cardiovascular diseases. Am J Clin Nutr 91: 1220-1226.

30. Kuehne LK, Reiber H, Bechter K, Hagberg L, Fuchs D (2015) Cerebrospinal fluid neopterin is brain-derived and not associated with blood-CSF barrier dysfunction in non-inflammatory affective and schizophrenic spectrum disorders. $J$ Psychiatr Res 63 : 141-142. [Crossref]

Copyright: (C2017 Silva TL. This is an open-access article distributed under the terms of the Creative Commons Attribution License, which permits unrestricted use, distribution, and reproduction in any medium, provided the original author and source are credited. 